\title{
Fatigue life for type 316L stainless steel under cyclic loading
}

\begin{abstract}
The paper presents the determination of fatigue life of $316 \mathrm{~L}$ stainless steel at room temperature. Plenty of steel in the world has been investigated for a lot of application in the science and technology market. The mechanisms of fatigue of 316L stainless steels were studied and investigated. Fatigue tests of specimens were performed in accordance with ASTM E466-96. The fatigue tests were performed in constant load amplitude, constant frequency of $5 \mathrm{~Hz}$ with load ratio $\mathrm{R}=0.1$. Fracture surface of specimens were examined by using Scanning Electron Microscope (SEM). The results showed that the endurance fatigue limit of 316L stainless steel was 146.45 MPa.
\end{abstract}

Keyword: Austenitic 316L stainless steel; Fatigue life; Fatigue limit; Scanning Electron Microscope (SEM) 